\title{
THE EFFECTS OF ACTIVE AND PASSIVE HYPERVENTILATION ON \\ CEREBRAL BLOOD FLOW, CEREBRAL OXYGEN CONSUMP- TION, CARDIAC OUTPUT, AND BLOOD PRESSURE OF NORMAL YOUNG MEN ${ }^{1}$
}

\author{
By SEYMOUR S. KETY AND CARL F. SCHMIDT \\ (From the Laboratory of Pharmacology, University of Pennsylvania, Philadelphia)
}

(Received for publication July 19, 1945)

The physiological effects of hyperventilation, long a subject of considerable interest to clinicians as well as physiologists, recently assumed a new practical importance in connection with military aviation. Here, in numerous situations, overbreathing may be encountered because of emotions or pain, or it may be induced voluntarily, and the results may be favorable or unfavorable, depending on circumstances. At altitudes at which anoxemia can be completely prevented by inhalaof $\mathrm{O}_{2}$, hyperventilation not only would exhaust the available supply of $\mathrm{O}_{2}$ at an unduly rapid rate, but also would have an adverse effect on the ability of the flyer to meet the exigencies of combat aviation $(1,2)$. But, at altitudes above 35,000 feet, where inhalation even of 100 per cent $\mathrm{O}_{2}$ cannot keep the alveolar oxygen tension from falling below the sea level normal, anoxemia can be prevented only by raising the pressure of the inhaled gas above the ambient pressure, or by making room for more $\mathrm{O}_{2}$ in the alveoli by blowing off $\mathrm{CO}_{2}$. If equipment for the former of these alternatives is not available, proves insufficient, suddenly becomes ineffective, or must be abandoned, the second may be the only possible means of avoiding incapacitating anoxemia. The relative dangers of anoxemia and acapnia then become a matter of immediate practical importance in connection with flight at extreme altitudes. If the cabin of the airplane is pressurized, the possibility of sudden decompression or the necessity for

\footnotetext{
1 The work described in this paper was done under a contract, recommended by the Committee on Medical Research, between the Office of Scientific Research and Development and the University of Pennsylvania. Financial support was also received from the National Committee for Mental Hygiene from funds granted by the Committee on Research in Dementia Praecox, founded by the Supreme Council, $33^{\circ}$ Scottish Rite, Northern Masonic Jurisdiction, U. S. A. Permission for publication has been granted.
}

abandoning the plane at an altitude at which hyperventilation may be necessary for survival, must always be borne in mind. If the plane is not pressurized the altitude tolerated by the flyer might be increased, or the time during which he could take effective action at a given high altitude might be prolonged, by means of hyperventilation. Finally, the flyer's ceiling can be increased by simply raising the pressure of $\mathrm{O}_{2}$ in the mask to a level higher than the ambient pressure, and this can be done by application of the added pressure either continuously or intermittently. The latter procedure is less uncomfortable than the former, but it is likely to cause considerably more hyperventilation.

For these reasons, not only the training of personnel for flight at extreme altitudes, but also the selection and procurement of equipment for such flight have called for fairly exact information concerning the physiological derangements brought about by hyperventilation. Meanwhile the importance of the same considerations in relation to the use of mechanical resuscitating devices has increased not only because of the greater need for resuscitation in connection with the current vogue of intravenous anesthesia, but also because of the recent availability of a number of more efficient devices for this purpose. Although a large amount of experimental work has been done in this field, both on laboratory animals and on man, the data hitherto available are not adequate for the present purpose. Thus, although passive hyperventilation is known to cause a profound fall in blood pressure in anesthetized animals (3) and man (4), due presumably to a decrease in vasomotor tone, voluntary hyperventilation by unanesthetized subjects apparently has no such effect (5). Whether this difference is due to the anesthetic or to the exercise involved in the voluntary process is unknown. Corresponding statements can be made 
about the effects on cardiac output, on which little information is available (6). One of the important effects claimed for hyperventilation is constriction of cerebral blood vessels, but the methods used to demonstrate this in man (increase in the femoral artery-internal jugular vein oxygen difference (7), increase in temperature in an artificially heated thermocouple inserted into an internal jugular vein (8), and decrease in the rate of displacement of cerebrospinal fluid during obstruction of both jugular veins in the neck (9)) are all open to criticism (10).

With the recent development of a method for measuring quantitatively the volume of blood flowing through the brain of an intact unanesthetized man (11), together with the ballistocardiographic method for estimating cardiac output (12) and standard means for determining arterial blood pressure, we had at our disposal for the first time the implements for securing unequivocal evidence on all of the points mentioned above. We could also calculate the amount of $\mathrm{O}_{2}$ used by the brain from the cerebral arteriovenous $\mathrm{O}_{2}$ difference, once the volume of cerebral blood flow was known. The total $\mathrm{O}_{2}$ uptake was readily measured, and the proportion of this represented by cerebral metabolism then could easily be determined. The corresponding figure for the proportion of cardiac output represented by total cerebral blood flow also could be computed from the ballistocardiogram and the measured volume of cerebral blood flow.

We have carried out these measurements in normal young men in the recumbent position at sea level and under 3 conditions, viz., at rest, during voluntary hyperventilation, and during approximately equal hyperventilation produced by a positive pressure resuscitating device, the General Electric Pneumolator. The experiments have been extended subsequently to conditions other than hyperventilation, which was chosen for first study because of the possible immediate military value of the information.

\section{METHODS}

Subjects. These were normal young men (conscientious objectors) 23 to 31 years of age. They reported about 9 A.M., without breakfast, and lay quietly on the ballistocardiographic bed for approximately an hour before the experiment began. Seven different subjects were used but complete data (i.e., under the 3 conditions noted above) could be obtained only in 5 .

Cerebral blood flow measurements. The nitrous oxide method was used substantially as already described (11), the concentration of $\mathrm{N}_{2} \mathrm{O}$ in the inhaled mixture being 15 per cent and that of $\mathrm{O}_{2} 21$ per cent in all cases. The balance was nitrogen. The period of measurement was 10 minutes. Samples of femoral arterial, and internal jugular venous blood were collected at $1,3,5$, and 10 minutes after the start of the $\mathrm{N}_{2} \mathrm{O}$ inhalation, the collections being accurately timed and synchronized. One such set was collected during quiet breathing, another (after about 5 minutes of quiet breathing and 10 minutes of hyperventilation with room air) during voluntary or passive hyperventilation. The other type of hyperventilation was tested on another day, after a rest period of 2 weeks or more. Each set of observations during hyperventilation, therefore, had its own set of control measurements during quiet breathing. Calculation of cerebral blood flow was carried out from the cerebral arteriovenous $\mathrm{N}_{2} \mathrm{O}$ difference substantially as described in our earlier report (11). The $\int_{0}^{t}(A-V) d t$ was measured simply from the area between the arterial and venous curves for $\mathrm{N}_{2} \mathrm{O}$ content, thus avoiding any assumptions as to the shape of these curves. ${ }^{2}$

Cardiac output. The horizontal ballistocardiograph was used (12). Records were made as follows: (1) after the subject had rested for about an hour and before the needles had been inserted; (2) during the last 5 minutes of the control cerebral blood flow determination; (3) during the last 5 minutes of the cerebral flow determination during hyperventilation; (4) during the minute immediately following discontinuance of passive hyperventilation. The calculations of cardiac output from these records have been corrected for dimensions of the living aorta (13). The complexes were distorted at the start of the inspiratory phase of breathing during passive hyperventilation, and the measurements were made from parts of the tracing that were free from obvious artefacts of this character.

Blood pressure. The femoral arterial needle was connected to the manifold, containing the battery of syringes used for collecting blood samples, by an annealed silver tube provided with an extra opening to which a mercury manometer was connected. This was heavily damped and was used for the direct measurement of mean blood pressure. Systolic and diastolic pressures were also estimated in the arm by the usual auscultatory method. These measurements were made at about the same time as the ballistocardiograms.

Oxygen consumption. This was estimated from a spirogram made with a conventional small basal metabolism

2 In some of the most recent experiments, it has been found that all assumptions as to the shape of the curves during the first minute of $\mathrm{N}_{2} \mathrm{O}$ inhalation can be avoided by taking an additional pair of samples at a slow constant rate throughout this period. The arteriovenous $\mathrm{N}_{2} \mathrm{O}$ difference in this pair immediately gives $\int_{0}^{1}(A-V) d t$. 
outfit over a period of 3 to 5 minutes immediately after the period of measurement of cerebral blood flow. During hyperventilation, these spirograms were too erratic to yield valid measurements of oxygen consumption.

Pulmonary ventilation. The spirograms from which oxygen consumption was measured gave reasonably accurate information on this point during quiet breathing and voluntary hyperventilation. During passive hyperventilation, the corresponding measurements were attempted by noting the time required for the exhalation of 65 liters into an accurately balanced spirometer. This method proved unsatisfactory because of a slight but steady leak of gas through the pneumolator during a considerable though variable part of the expiratory phase. Consequently, we have no data on this point.

Collection and analysis of blood samples. Steel needles of 18 gauge were introduced into an internal jugular vein and a femoral artery after infiltration of the tissues with 1 per cent procaine. They were filled with sterile heparin solution (Abbott) by means of a syringe and promptly connected to the tube and manifold system. The latter was provided with a heparin-containing syringe by means of which fresh blood was drawn into relation with the collecting syringe just before the sample was collected and was replaced with a heparin-blood mixture just afterward. The usual aseptic precautions were observed throughout. The syringes used to collect the samples were of $10 \mathrm{ml}$. size, all glass construction. Each contained a mercury seal amounting to about $1 \mathrm{ml}$. and a little heparin. After some early experiments showed extraordinarily low figures for arterial $\mathrm{pH}$ and $\mathrm{pCO}_{2}$, we took special pains to be certain that all traces of acid were removed from the freshly washed mercury before it was used.

The blood samples, measuring about 6 to $8 \mathrm{ml}$. and rendered incoagulable with heparin, were analyzed for $\mathrm{N}_{2} \mathrm{O}$ content by the method previously used (11) and for $\mathrm{O}_{2}$ and $\mathrm{CO}_{2}$ content by the manometric method of Van Slyke (14). Separate $2 \mathrm{ml}$. samples were used for $\mathrm{N}_{2} \mathrm{O}$. Analyses for $\mathrm{O}_{2}$ and $\mathrm{CO}_{2}$ were made on at least the first and last pair of samples of each cerebral flow determination, and the values reported represent the respective averages. The hydrogen ion concentration of the samples was determined on the whole blood by means of a MacInnes-Belcher glass electrode and a Leeds and Northrup electronic potentiometer. These readings were made at $38^{\circ} \mathrm{C}$., and with their aid it was possible to calculate the $\mathrm{CO}_{2}$ tension $\left(\mathrm{pCO}_{2}\right)$ by means of the nomograms of Peters and Van Slyke (14). The blood samples were kept on ice between the time of collection and the time of completion of the analyses. The estimations of $\mathrm{O}_{2}, \mathrm{CO}_{2}$ content, and $\mathrm{pH}$ were begun at once, and all analyses were completed within 12 hours of the collection of the sample.

Other observations. In every experiment, attempts were made to determine the degree of mental alertness by noting the responses to questions and by observing the promptness with which instructions were followed. Signs of tetany were watched for during hyperventilation. The presence of indwelling needles in the internal jugular vein and the femoral artery precluded the use of the usual tests for cerebral functions.

The course of a typical experiment was as follows: The subject, who had had no food since the preceding evening, clad himself in light operating clothes and lay down on the ballistocardiographic bed. About an hour later ballistocardiogram I was recorded. The face mask was then applied and connected to a $\mathrm{T}$-piece through which instantaneous shift could be made between ambient air and the $\mathrm{N}_{2} \mathrm{O}-\mathrm{O}_{2}-\mathrm{N}_{2}$ mixture. The needles were then inserted in the jugular vein and femoral artery and connected to their respective manifolds. The subject was assured that no other disquieting procedures would be carried out and the first (control) 10-minute period of measurement of cerebral blood flow was then begun; after the pair of blood samples had been collected at 5 minutes, the ballistocardiogram and blood pressure measurements were repeated. After the final (10-minute) pair of blood samples was collected, the inhalation of $\mathrm{N}_{2} \mathrm{O}$ was discontinued in favor of room air, and when a few more minutes had elapsed, the control spirogram was made. Following this, hyperventilation with room air was begun and was continued for 10 minutes. Voluntary hyperventilation was carried out in time to a bell ringing every 10 seconds, the subject being instructed to take a comfortably deep inspiration and to exhale at a rate that would complete the cycle before the next signal. Passive hyperventilation was carried out with a positive pressure of $150 \mathrm{~mm}$. ( 6 inches) $\mathrm{H}_{2} \mathrm{O}$ which was found by experience to produce about the same degree of alkalosis as the described voluntary procedure. The gas used for this purpose was ambient air compressed in tanks of the same type as those containing the $\mathrm{N}_{2} \mathrm{O}-\mathrm{O}_{2}-\mathrm{N}_{2}$ mixture. At the end of this 10 minutes of hyperventilation with air, an extra sample of jugular blood was collected to give the base-line for the next $\mathrm{N}_{2} \mathrm{O}$ period. Then the $\mathrm{N}_{2} \mathrm{O}-\mathrm{O}_{2}-\mathrm{N}_{2}$ mixture was substituted for room air, and the second period of blood flow measurement was begun; the hyperventilation was maintained as nearly constant as possible during this time. Again the ballistocardiographic and blood flow estimations were carried out during the latter 5 minutes of this period. At the end of this time, room air was substituted for the $\mathrm{N}_{2} \mathrm{O}-\mathrm{O}_{2}-\mathrm{N}_{2}$ mixture with the hyperventilation continuing as nearly constant as possible, and the second spirogram was made. Then the hyperventilation was discontinued, and the subject was instructed to relax completely. Usually, there was a brief apnea at this time and in some cases another ballistocardiogram was made as the subject began to breathe again. The total elapsed time was about 3 to $3 \frac{1}{2}$ hours, of which about half was comprised in the periods of experimental observations. The hyperventilation period lasted 20 to 30 minutes; hence, the voluntary hyperpnea had to be only of moderate intensity, which the passive process was adjusted to resemble.

\section{RESULTS}

The essential data from 12 successful experiments are presented in Tables I, II, and III, and 
TABLE I

Effects of active and passive hyperventilation on arterial and cerebral venous blood constituents

\begin{tabular}{|c|c|c|c|c|c|c|c|c|c|c|c|c|c|c|c|c|c|c|c|c|c|}
\hline \multirow{3}{*}{\multicolumn{2}{|c|}{ Subject }} & \multirow{2}{*}{\multicolumn{2}{|c|}{$\begin{array}{c}\text { Pulmo- } \\
\text { nary } \\
\text { ventilation }\end{array}$}} & \multicolumn{4}{|c|}{ Blood $\mathrm{CO}_{2}$ content } & \multirow{2}{*}{\multicolumn{2}{|c|}{$\begin{array}{c}\text { Cerebral } \\
\text { A-V } \\
\text { difference }\end{array}$}} & \multicolumn{4}{|c|}{ Blood $\mathrm{O}_{2}$ content } & \multirow{2}{*}{\multicolumn{2}{|c|}{$\begin{array}{c}\text { Cerebral } \\
\text { A-V } \\
\text { difference }\end{array}$}} & \multirow{2}{*}{\multicolumn{2}{|c|}{$\begin{array}{c}\text { Cerebral } \\
\text { R.Q. }\end{array}$}} & \multicolumn{4}{|c|}{ Blood pH } \\
\hline & & & & \multicolumn{2}{|c|}{ Arterial } & \multicolumn{2}{|c|}{$\begin{array}{l}\text { Internal } \\
\text { jugular }\end{array}$} & & & \multicolumn{2}{|c|}{ Arterial } & \multicolumn{2}{|c|}{$\begin{array}{l}\text { Internal } \\
\text { jugular }\end{array}$} & & & & & \multicolumn{2}{|c|}{ Arterial } & \multicolumn{2}{|c|}{$\begin{array}{l}\text { Internal } \\
\text { jugular }\end{array}$} \\
\hline & & C & $\mathbf{H}$ & C & $\mathbf{H}$ & C & $\mathbf{H}$ & C & $\mathbf{H}$ & C & $\mathbf{H}$ & C & $\mathbf{H}$ & C & $\mathbf{H}$ & C & $\mathbf{H}$ & C & $\mathbf{H}$ & C & $\mathbf{H}$ \\
\hline & & \multicolumn{2}{|c|}{$\begin{array}{l}\text { liters per } \\
\text { minute }\end{array}$} & \multicolumn{4}{|c|}{ volumes per cent } & \multicolumn{2}{|c|}{$\begin{array}{l}\text { volumes } \\
\text { per cent }\end{array}$} & \multicolumn{4}{|c|}{ oolumes per cent } & \multicolumn{2}{|c|}{$\begin{array}{l}\text { volumes } \\
\text { per cent }\end{array}$} & & & & & & \\
\hline \multirow[t]{2}{*}{ 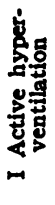 } & $\begin{array}{l}\text { S. H. } \\
\text { A. C. } \\
\text { L. E. } \\
\text { M. H. } \\
\text { D. M. } \\
\text { W. H. } \\
\text { W. G. }\end{array}$ & $\begin{array}{l}8.2 \\
8.6 \\
7.0 \\
7.9 \\
7.5 \\
9.1\end{array}$ & $\begin{array}{c}25.3 \\
12.1 \\
12.3 \\
7.6^{*} \\
15.2 \\
20.2\end{array}$ & $\begin{array}{l}51.4 \\
51.7 \\
49.4 \\
52.2 \\
49.1 \\
50.0 \\
51.1\end{array}$ & $\begin{array}{l}37.9 \\
42.5 \\
41.9 \\
48.7 \\
39.3 \\
40.5 \\
45.1\end{array}$ & $\begin{array}{l}55.4 \\
55.6 \\
54.5 \\
58.4 \\
53.8 \\
55.0 \\
57.3\end{array}$ & $\begin{array}{l}47.7 \\
53.9 \\
52.8 \\
58.0 \\
49.1 \\
51.6 \\
55.7\end{array}$ & $\begin{array}{l}4.0 \\
4.0 \\
5.1 \\
6.2 \\
4.7 \\
5.0 \\
6.2\end{array}$ & $\begin{array}{r}9.8 \\
11.4 \\
10.9 \\
9.3 \\
9.8 \\
11.1 \\
10.6\end{array}$ & $\begin{array}{l}17.0 \\
17.8 \\
17.5 \\
17.0 \\
18.7 \\
18.5 \\
18.0\end{array}$ & $\begin{array}{l}18.4 \\
18.8 \\
17.4 \\
17.6 \\
19.4 \\
19.4 \\
18.8\end{array}$ & $\begin{array}{l}11.0 \\
12.0 \\
11.8 \\
10.9 \\
12.6 \\
12.1 \\
11.4\end{array}$ & $\begin{array}{l}9.4 \\
8.2 \\
6.6 \\
8.1 \\
8.4 \\
8.4 \\
7.8\end{array}$ & $\begin{array}{l}6.0 \\
5.8 \\
5.7 \\
6.1 \\
6.1 \\
6.4 \\
6.6\end{array}$ & $\begin{array}{r}9.0 \\
10.6 \\
10.8 \\
9.5 \\
11.0 \\
11.0 \\
11.0\end{array}$ & $\begin{array}{l}0.67 \\
0.69 \\
0.90 \\
1.02 \\
0.77 \\
0.78 \\
0.94\end{array}$ & $\begin{array}{l}1.09 \\
0.98 \\
1.01 \\
0.98 \\
0.89 \\
1.01 \\
0.97\end{array}$ & $\begin{array}{l}7.30 \\
7.29 \\
7.39 \\
7.43 \\
7.38 \\
7.39\end{array}$ & $\begin{array}{l}7.44 \\
7.52 \\
7.52 \\
7.53 \\
7.57 \\
7.56\end{array}$ & $\begin{array}{l}7.36 \\
7.41 \\
7.35 \\
7.34\end{array}$ & $\begin{array}{l}7.46 \\
7.45 \\
7.46\end{array}$ \\
\hline & Mean & 8.1 & 15.5 & 50.7 & 42.3 & 55.7 & 52.7 & 5.0 & 10.4 & 17.8 & 18.5 & 11.7 & 8.1 & 6.1 & 10.4 & $0.82 t$ & 0.99 & 7.37 & 7.53 & 7.36 & 7.46 \\
\hline \multirow{2}{*}{ 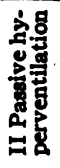 } & $\begin{array}{l}\text { S. H. } \\
\text { L. E. } \\
\text { M. H. } \\
\text { D. M. } \\
\text { W. H. }\end{array}$ & $\begin{array}{l}6.5 \\
8.1 \\
6.8 \\
6.5 \\
7.8\end{array}$ & & $\begin{array}{l}45.7 \\
51.1 \\
49.2 \\
49.7 \\
50.5\end{array}$ & $\begin{array}{l}37.4 \\
40.1 \\
44.3 \\
41.4 \\
40.8\end{array}$ & $\begin{array}{l}\mathbf{5 3 . 2} \\
\mathbf{5 8 . 4} \\
\mathbf{5 5 . 7} \\
\mathbf{5 6 . 0} \\
\mathbf{5 7 . 9}\end{array}$ & $\begin{array}{l}48.3 \\
52.1 \\
54.7 \\
53.7 \\
51.8\end{array}$ & $\begin{array}{l}7.5 \\
7.3 \\
6.5 \\
6.3 \\
7.4 \\
\end{array}$ & $\begin{array}{l}10.9 \\
12.0 \\
10.4 \\
12.3 \\
11.0\end{array}$ & $\begin{array}{l}17.7 \\
17.6 \\
16.7 \\
19.8 \\
18.2\end{array}$ & $\begin{array}{l}18.5 \\
18.7 \\
17.2 \\
20.1 \\
18.8\end{array}$ & $\begin{array}{r}10.6 \\
9.4 \\
9.5 \\
13.0 \\
11.5\end{array}$ & $\begin{array}{l}7.8 \\
7.0 \\
6.3 \\
7.6 \\
7.7\end{array}$ & $\begin{array}{l}7.1 \\
8.2 \\
7.2 \\
6.8 \\
6.7\end{array}$ & $\begin{array}{l}10.7 \\
11.7 \\
10.9 \\
12.5 \\
11.1\end{array}$ & $\begin{array}{l}1.05 \\
0.89 \\
0.90 \\
0.93 \\
1.10\end{array}$ & $\begin{array}{l}1.02 \\
1.03 \\
0.96 \\
0.98 \\
0.99\end{array}$ & $\begin{array}{l}7.43 \\
7.42 \\
7.35 \\
7.37 \\
7.38\end{array}$ & $\begin{array}{l}7.58 \\
7.60 \\
7.50 \\
7.51 \\
7.63\end{array}$ & $\begin{array}{l}7.42 \\
7.34 \\
7.30 \\
7.31 \\
7.34\end{array}$ & $\begin{array}{l}7.49 \\
7.49 \\
7.40 \\
7.58\end{array}$ \\
\hline & Mean & 7.1 & & 49.2 & 40.8 & 56.2 & 52.1 & 7.0 & 11.3 & 18.0 & 18.7 & 10.8 & 7.3 & 7.2 & 11.4 & 0.97 & 1.00 & 7.39 & 7.56 & 7.34 & 7.49 \\
\hline
\end{tabular}

$\mathrm{C}=$ control. $\quad \mathrm{H}=$ hyperventilation. $\mathrm{R} . \mathrm{Q} .=$ respiratory quotient. Further data in Table III

* This subject became drowsy during the period of hyperventilation and had to be reminded regularly of what was expected of him. Even though the respiratory minute volume seems to have decreased there was, by virtue of the slower and deeper respiration in this period, a real increase in effective ventilation as shown by the blood changes.

$t$ In this group of determinations oiled syringes were not used with consequent slight loss of $\mathrm{CO}_{2}$ sufficient, however, to depress the R.Q. in some cases. This defect was corrected in subsequent experiments.

TABLE II

Effects of active and passive hyperventilation on cardiac output, pulse and blood pressure

\begin{tabular}{|c|c|c|c|c|c|c|c|c|c|c|c|c|c|c|c|c|c|c|c|c|c|}
\hline \multirow{2}{*}{\multicolumn{2}{|c|}{ Subject }} & \multicolumn{4}{|c|}{ Stroke volume } & \multicolumn{4}{|c|}{ Cardiac output } & \multicolumn{4}{|c|}{ Pulse rate } & \multicolumn{4}{|c|}{$\begin{array}{c}\text { Mean arterial } \\
\text { blood pressure } \\
\text { direct }\end{array}$} & \multicolumn{4}{|c|}{ Auscultatory blood pressure } \\
\hline & & I & II & III & IV & I & II & III & IV & I & II & III & IV & I & II & III & IV & I & II & III & IV \\
\hline & & \multicolumn{4}{|c|}{$m l}$. & \multicolumn{4}{|c|}{ liters per minute } & & & & & \multicolumn{4}{|c|}{$m m . H g$} & \multicolumn{4}{|c|}{$m m . H_{B}$} \\
\hline \multirow{2}{*}{ 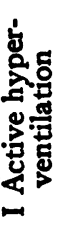 } & $\begin{array}{l}\text { S. H. } \\
\text { A. C. } \\
\text { L. E. } \\
\text { M. H. } \\
\text { D. M. } \\
\text { W. H. }\end{array}$ & $\begin{array}{l}77 \\
72 \\
71 \\
70 \\
68\end{array}$ & $\begin{array}{l}76 \\
63 \\
70 \\
69 \\
74\end{array}$ & $\begin{array}{l}75 \\
56 \\
70 \\
64 \\
\\
60\end{array}$ & & $\begin{array}{l}5.5 \\
6.5 \\
5.8 \\
4.1 \\
4.5\end{array}$ & $\begin{array}{l}4.9 \\
5.2 \\
4.9 \\
4.5 \\
4.9\end{array}$ & $\begin{array}{l}5.6 \\
5.3 \\
4.6 \\
3.8 \\
5.7\end{array}$ & & $\begin{array}{l}72 \\
90 \\
82 \\
58 \\
66\end{array}$ & $\begin{array}{l}64 \\
82 \\
70 \\
65 \\
\\
66\end{array}$ & $\begin{array}{l}75 \\
94 \\
65 \\
59 \\
95\end{array}$ & & $\begin{array}{l}83 \\
92 \\
90\end{array}$ & $\begin{array}{l}86 \\
88 \\
95 \\
86\end{array}$ & $\begin{array}{r}97 \\
96 \\
93 \\
97 \\
93 \\
112\end{array}$ & & $\begin{array}{l}118 / 70 \\
105 / 78\end{array}$ & $\begin{array}{l}117 / 80 \\
105 / 78 \\
112 / 80 \\
100 / 70\end{array}$ & $\begin{array}{l}130 / 95 \\
120 / 70 \\
105 / 90 \\
100 / 74 \\
135 / 105\end{array}$ & \\
\hline & Mean & 72 & 70 & 65 & & 5.3 & 4.9 & 5.0 & & 74 & 69 & 78 & & \multicolumn{2}{|c|}{88} & 98 & & \multicolumn{2}{|c|}{$110 / 76$} & $118 / 87$ & \\
\hline \multirow{2}{*}{ 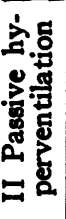 } & $\begin{array}{l}\text { S. H. } \\
\text { L. E. } \\
\text { M. H. } \\
\text { D. M. } \\
\text { W. H. }\end{array}$ & $\begin{array}{l}68 \\
71 \\
70 \\
74 \\
76\end{array}$ & $\begin{array}{l}63 \\
63 \\
70 \\
70 \\
70\end{array}$ & $\begin{array}{l}49 \\
55 \\
53 \\
65 \\
53\end{array}$ & $\begin{array}{l}62 \\
63 \\
53 \\
71\end{array}$ & $\begin{array}{l}3.6 \\
5.4 \\
4.5 \\
5.7 \\
4.3\end{array}$ & $\begin{array}{l}3.4 \\
5.3 \\
4.2 \\
4.9 \\
4.5\end{array}$ & \begin{tabular}{|l|}
3.1 \\
4.3 \\
3.8 \\
4.8 \\
3.8
\end{tabular} & $\begin{array}{l}3.4 \\
4.8 \\
3.9 \\
5.1\end{array}$ & $\begin{array}{l}53 \\
76 \\
64 \\
77 \\
56\end{array}$ & $\begin{array}{l}54 \\
84 \\
60 \\
70 \\
65\end{array}$ & $\begin{array}{l}64 \\
79 \\
71 \\
74 \\
71\end{array}$ & $\begin{array}{l}55 \\
76 \\
73 \\
72\end{array}$ & & $\begin{array}{r}85 \\
94 \\
84 \\
94 \\
104\end{array}$ & $\begin{array}{r}86 \\
95 \\
91 \\
99 \\
125\end{array}$ & & $\begin{array}{r}95 / 75 \\
105 / 80\end{array}$ & $\begin{array}{r}95 / 65 \\
110 / 65 \\
112 / 85 \\
115 / 95\end{array}$ & $\begin{array}{r}90 / 70 \\
105 / 75 \\
102 / 95 \\
120 / 95\end{array}$ & \\
\hline & Mean & 72 & 67 & 55 & 62 & 4.7 & 4.5 & 4.0 & 4.3 & 65 & 67 & 72 & 69 & & 92 & 99 & & \multicolumn{2}{|c|}{$107 / 78$} & $104 / 84$ & \\
\hline
\end{tabular}

$I$ = control period (just before start of control blood flow measurement); II = latter 5 minutes of period of control blood flow measurement; III = latter 5 minutes of period of blood flow measurement during hyperventilation; IV $=$ during first minute after cessation of hyperventilation. 
TABLE III

Effects of active and passive hyperventilation on cerebral blood flow and cerebral oxygen consumption

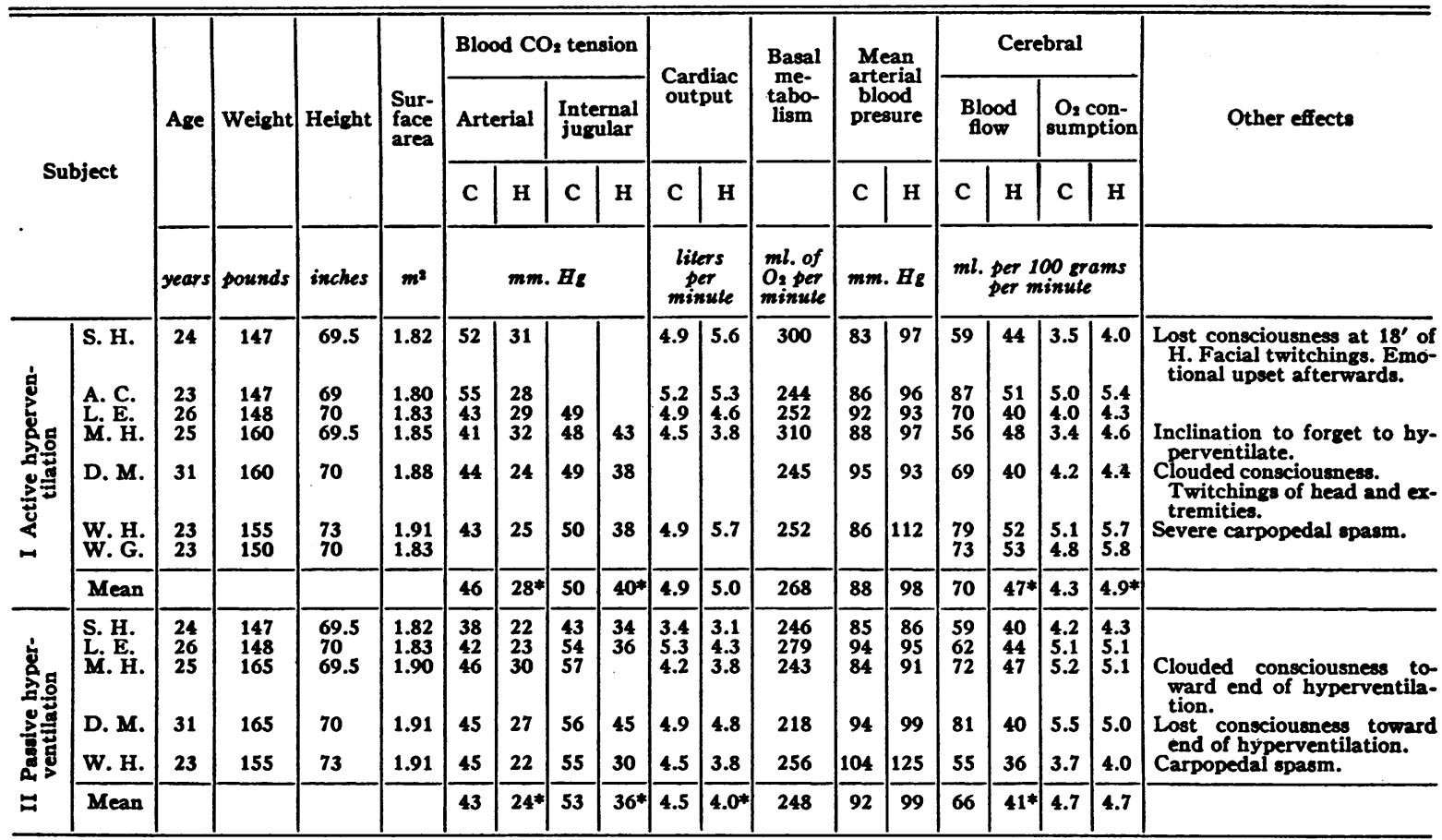

$\mathrm{C}=$ control. $\mathrm{H}=$ hyperventilation. $\quad$ * This represents statistically significant changes.

TABLE IV

Percentile changes induced by active $(A)$ and passive $(P)$ hyperventilation

\begin{tabular}{|c|c|c|c|c|c|c|c|c|c|c|c|c|c|c|c|c|c|c|}
\hline \multirow{3}{*}{ Subject } & \multicolumn{6}{|c|}{ Arterial } & \multirow{2}{*}{\multicolumn{2}{|c|}{$\begin{array}{c}\begin{array}{c}\text { Internal } \\
\text { jugular }\end{array} \\
\mathrm{pCO}_{2}\end{array}$}} & \multicolumn{6}{|c|}{ Cerebral } & \multirow{2}{*}{\multicolumn{2}{|c|}{$\begin{array}{l}\text { Cardiac } \\
\text { output }\end{array}$}} & \multirow{2}{*}{\multicolumn{2}{|c|}{$\begin{array}{l}\text { Blood } \\
\text { pressure }\end{array}$}} \\
\hline & \multicolumn{2}{|c|}{$\mathrm{CO}_{2}$ content } & \multicolumn{2}{|c|}{$\mathrm{pCO}_{2}$} & \multicolumn{2}{|c|}{$\left(\mathrm{H}^{+}\right)$} & & & \multicolumn{2}{|c|}{$\begin{array}{c}\text { A-V } \\
\text { difference } \\
\mathrm{O}_{2}\end{array}$} & \multicolumn{2}{|c|}{ Blood flow } & \multicolumn{2}{|c|}{$\mathrm{O}_{2}$ uptake } & & & & \\
\hline & $\mathbf{A}$ & $\mathbf{P}$ & $\mathbf{A}$ & $\mathbf{P}$ & $\mathbf{A}$ & $\mathbf{P}$ & $\mathbf{A}$ & $\mathbf{P}$ & $\mathbf{A}$ & $\mathbf{P}$ & $\mathbf{A}$ & $\mathbf{P}$ & $\mathbf{A}$ & $\mathbf{P}$ & $\mathbf{A}$ & $\mathbf{P}$ & $\mathbf{A}$ & $\mathbf{P}$ \\
\hline $\begin{array}{l}\text { S. H. } \\
\text { L. E. } \\
\text { M. H. } \\
\text { D. M. } \\
\text { W. H. }\end{array}$ & $\begin{array}{l}-26 \\
-15 \\
-7 \\
-20 \\
-19\end{array}$ & $\begin{array}{l}-18 \\
-22 \\
-10 \\
-17 \\
-19\end{array}$ & $\begin{array}{l}-40 \\
-33 \\
-22 \\
-45 \\
-42\end{array}$ & $\begin{array}{l}-42 \\
-45 \\
-35 \\
-40 \\
-50\end{array}$ & $\begin{array}{l}-28 \\
-27 \\
-19 \\
-36 \\
-32\end{array}$ & $\begin{array}{l}-30 \\
-34 \\
-29 \\
-28 \\
-45\end{array}$ & $\begin{array}{l}-10 \\
-22 \\
-24\end{array}$ & $\begin{array}{l}-21 \\
-33 \\
-20 \\
-45\end{array}$ & $\begin{array}{r}+50 \\
+90 \\
+56 \\
+80 \\
+72\end{array}$ & $\begin{array}{l}+51 \\
+43 \\
+52 \\
+84 \\
+66\end{array}$ & $\begin{array}{l}-25 \\
-43 \\
-14 \\
-42 \\
-34\end{array}$ & $\begin{array}{l}-32 \\
-29 \\
-35 \\
-51 \\
-34\end{array}$ & $\begin{array}{r}+14 \\
+\quad 7 \\
+35 \\
+\quad 5 \\
+12\end{array}$ & $\begin{array}{r}+2 \\
0 \\
-2 \\
-9 \\
+8\end{array}$ & $\begin{array}{r}\text { per } m \\
+14 \\
-6 \\
-15 \\
+16\end{array}$ & $\begin{array}{l}\text { minute } \\
-9 \\
-19 \\
-10 \\
-2 \\
-15\end{array}$ & $\begin{array}{l}+17 \\
+\quad 1 \\
+10 \\
+2 \\
+30\end{array}$ & $\begin{array}{r}+1 \\
+1 \\
+8 \\
+5 \\
+20\end{array}$ \\
\hline Mean & -17 & -17 & -36 & -43 & -28 & -33 & -19 & -30 & +70 & +59 & -32 & -36 & +15 & 0 & +2 & -11 & +12 & +8 \\
\hline
\end{tabular}

$A=$ active (voluntary). $\mathbf{P}=$ passive (pneumolator).

the most significant effects of hyperventilation are summarized in Table IV. The gaps in the tables are due to lack of pertinent information for various reasons. The estimations of $\mathrm{pH}$ and $\mathrm{pCO}_{2}$ in the blood in the first 2 experiments (Tables I and III) were invalidated by failure to wash the mercury completely free of acid after cleansing it in towers of dilute nitric acid and distilled water in the usual manner; as a result, the $\mathrm{pH}$ values were abnormally low, but this oversight was remedied for the subsequent experiments. The relatively high values for arterial $\mathrm{CO}_{2}$ content and tension during quiet breathing (Table I and III) are most probably referable to 
the dead space of the mask. The actual figures for the $\mathrm{N}_{2} \mathrm{O}$ content of the various blood samples are omitted from the tables for the sake of simplicity, but representative examples are shown in Figure 1.

The intensity of the hyperventilation can be judged better from the changes in $\mathrm{CO}_{2}$ content and acidity of the arterial blood than from the figures given for pulmonary ventilation. This is glaringly evident in the case of active hyper-
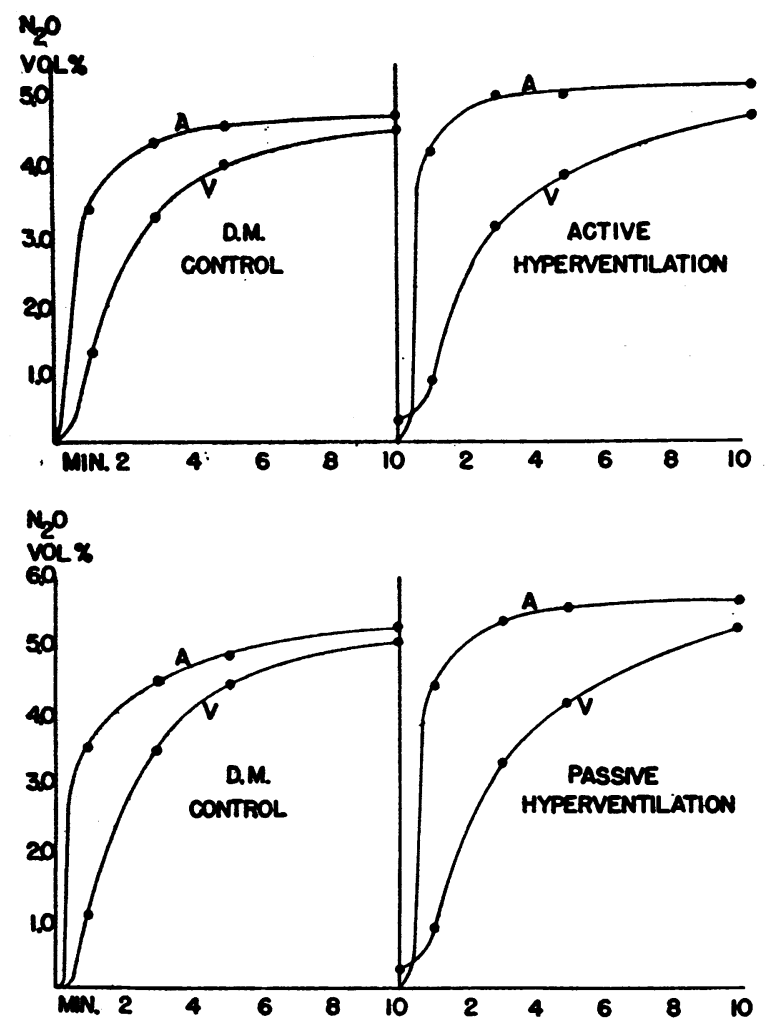

Fig. 1. Nitrous Oxide Concentration Curves for Arterial and Internal Jugular Blood from which Cerebral Blood Flow Is Calculated

Two typical experiments on the same subject (D. M.) performed 3 weeks apart are illustrated. There is a lapse of about 20 minutes between the control and hyperventilation periods, during which nitrous oxide is cleared completely from arterial and almost completely from cerebral venous blood. Cerebral blood flow is calculated as previously derived (11) from $\frac{100 S\left(V_{10}-V_{0}\right)}{\int_{0}^{10}(A-V) d t}$ the constant $S$ being a partition coefficient for nitrous oxide between brain and blood. It is apparent by inspection that during hyperventilation, the area between the arterial and venous curves $\left(\int(A-V) d t\right)$ increases considerably indicating a decrease in cerebral blood flow. ventilation by $M . H$. (Table I), which indicates that the values listed for pulmonary ventilation should not be regarded as precise criteria of the degree of alkalosis involved in these experiments. The reason for this discrepancy is our practice of measuring the ventilation at a period different from that involved in the collection of the blood samples. The degree of voluntary hyperventilation could not be kept constant throughout the entire period which lasted more than 20 minutes. In the case of passive hyperventilation, we have to depend entirely on the blood changes for orientation on this point.

\section{DISCUSSION}

The data presented in the tables afford a considerably deeper insight into the physiological readjustments evoked by hyperventilation in normal man than had been possible hitherto because they include actual figures for the behavior of cerebral blood flow. They also permit a set of calculations, previously impossible, of the fractions of the total cardiac output and total oxygen consumption that are accounted for by the blood flow and oxygen uptake of the brains of normal intact men. The importance of each of these items of information is attested by the existence of a considerable literature bearing upon it. We believe, therefore, a full discussion of an interpretation of the probable significance of our findings to be justified.

The validity of these findings rests upon the competence of the methods employed. With the exception of the measurements of cerebral blood flow and cardiac output, these were standard procedures that call for no further comment. Our method for measuring cerebral blood flow, as pointed out elsewhere (11), has been subjected to calibration against direct measurement of cerebral blood flow in monkeys and has back of it, therefore, an assurance of fundamental accuracy that is rare among methods advanced for.clinical use. Further experience with the method has led to several improvements in detail but to no fundamental change in principle or interpretation. The ballistocardiographic method for measuring cardiac output has been considered in detail in a recent symposium (15) where a full account of its strengths and weaknesses was presented. The 
consensus appears to be that the results obtained are probably trustworthy, provided that neither hypotension nor tachycardia is present. Our experiments clearly fall into this category.

Changes in composition of blood. The actual data are given in Table $I$, and the percentile changes are summarized in Table IV. The most significant findings are those for cerebral arteriovenous differences for $\mathrm{O}_{2}$ and $\mathrm{CO}_{2}$, which underwent a consistent and considerable increase during hyperventilation of either type. Since mean blood pressure never fell and usually rose at the same time (Table II), this particular effect cannot be ascribed to depression of the general circulation but must have been due either to an increase in the rate of cerebral metabolism, or to an intrinsic diminution in the volume of blood passing through the brain, i.e., cerebral vasoconstriction, or perhaps to both. The data shown in Table III indicate that the second of these was the dominant factor. These findings and their interpretation are fully confirmatory, therefore, of those of others $(7,25$, 26)..$^{3}$ The indicated diminutions in $\mathrm{CO}_{2}$ content and hydrogen ion concentration in both arterial and venous bloods are as expected, as are also the slight increases in arterial $\mathrm{O}_{2}$ content (in view of the high resting arterial $\mathrm{CO}_{2}$ content, which was attributed to the dead space of the mask).

The behavior of the cerebral respiratory quotient deserves a brief comment. This factor was practically the expected 1.0 in all cases except 4 out of the first series of resting (control) observations (Table I). The first 2 of these probably can be discounted because they were the instances of failure to remove all traces of acid from the mercury used to seal the syringes. The other 2 may have been related to the avoidance of oil to lubricate the syringes for fear that it would dissolve significant amounts of $\mathrm{N}_{2} \mathrm{O}$ out of the blood samples. After these low values were obtained, we investigated this possibility and found it to be

\footnotetext{
s It is noteworthy, however, that actual calculations of cerebral metabolism in these experiments showed it to undergo a consistent and significant increase during active hyperventilation with no appreciable change during the passive process (Tables III and IV). This is a concrete example of the untrustworthiness of the cerebral arteriovenous oxygen difference as a criterion of the behavior of either cerebral metabolism or cerebral blood flow, as pointed out in an earlier publication (18).
}

insignificant. From this time on, the syringes were lubricated and no more low respiratory quotients were obtained. The behavior of $\mathrm{CO}_{2}$ naturally was not as important for our purposes as was that of $\mathrm{N}_{2} \mathrm{O}$.

Cerebral blood flow. The data are presented in Table III and are expressed on a percentile basis in Table IV. Without exception, cerebral blood flow diminished during hyperventilation. The degree of the change is somewhat surprising when it is remembered that these hyperpneas were only moderately intense. Definite signs of tetany were seen in only 4 of the 11 experiments and in only 3 of the 7 subjects, which may be taken as evidence that we were not dealing with an extreme alkalosis or acapnia. Yet the diminutions in cerebral blood flow during voluntary hyperpnea ranged from 14 to 43 and averaged 32 per cent, while during passive hyperventilation, the corresponding range in the same subjects was 29 to 51 , and the average was 36 per cent. A change of this magnitude can scarcely be ignored in allocating responsibility for deterioration in cerebral functions during hyperventilation. As shown in Table III, signs of impairment of cortical activity were evident during hyperventilation in 5 of the experiments even by the crude methods which we used to detect such changes. The use of more exact tests for cerebral performance was precluded by the experimental conditions (particularly the indwelling needles and the mask).

The possible effects of hyperventilation on cerebral functions are so numerous and so poorly understood that it is impossible at present to evaluate the part played by any single factor with even approximate accuracy. Alkalosis, diminution in $\mathrm{pCO}_{2}$, changes in the cerebral $\mathrm{O}_{2}-$ glucose ratios and respiratory quotients, all are elicited concurrently during hyperventilation $(25,26)$, and there is insufficient evidence by which to assess the relative importance of any of these. One group has found during hyperventilation a better correlation of electroencephalographic patterns and impaired consciousness with lowered $\mathrm{pCO}_{2}$ in the internal jugular vein than with lowered $\mathrm{pO}_{2}$ $(25,26)$. Nevertheless, it seems to us that a diminution in cerebral blood flow of the order of 30 per cent, while cerebral $\mathrm{O}_{2}$ consumption is unchanged or increased (Tables III and IV), should 
be capable of leading to a diminution in mean cortical $\mathrm{pO}_{2}$ sufficient to constitute a major factor in the concurrent deterioration of cortical functions. If one assumes that the relation of cerebral venous $\mathrm{pO}_{2}$ to mean cortical $\mathrm{pO}_{2}$ remains unchanged during hyperventilation, one can estimate the diminution in the latter from the observed decrease in the former. The observed mean changes in cerebral venous $\mathrm{O}_{2}$ content (Table I) were from 11.7 to 8.1 volumes per cent during voluntary and from 10.8 to 7.3 volumes per cent during passive hyperventilation-decreases of 31 and 32 per cent. The corresponding changes in $\mathrm{pO}_{2}$ on the nomogram of Peters and Van Slyke (14) are from 35 to 22 and from 33 to $19 \mathrm{~mm}$. $\mathrm{Hg}$ respectively-decreases of 37 and 42 per cent.

We have as yet no direct information concerning the relation of cerebral venous $\mathrm{pO}_{2}$ to cortical $\mathrm{pO}_{2}$ in man. According to recent studies made with an oxygen electrode applied to the exposed brain of the cat, cortical $\mathrm{pO}_{2}$ varies over a wide range, depending both on the proximity of the electrode to a blood vessel (16) and the state of functional activity of the underlying tissue (17), but there was a clear tendency for the $\mathrm{pO}_{2}$ in the cortex to be lower than that in the cerebral veins (16). If a similar relation existed in our subjects, the observed decreases in cerebral venous $\mathrm{pO}_{2}$ would signify that cortical $\mathrm{pO}_{2}$ had fallen to an even lower level and signs of anoxia would not be surprising. As a matter of fact, our figures both for mean cerebral venous $\mathrm{O}_{2}$ content during hyperventilation ( 7.7 volumes per cent) and its decrease below the control level ( 32 per cent) are practically identical with the corresponding values (7.9 and 32 volumes per cent -respectively) reported (7) from experiments on subjects inhaling mixtures having an $\mathrm{O}_{2}$ content of only 6 to 8 per cent. The associated cerebral anoxia undoubtedly was less severe in our subjects than in theirs because of the higher level of $\mathrm{pO}_{2}$ at the arterial end of the capillaries in ours, but the severity of the systemic anoxemia required to elicit such a drop in cerebral venous $\mathrm{O}_{2}$ content at least indicates that this change was not inconsequential. Even though we are unable to estimate the part played by cortical anoxia due to diminution in cerebral blood flow in the deterioration in cerebral functions associated with hyper- ventilation, it seems proper to point out that a major physiological adjustment is involved in addition to the biochemical changes evident in the blood.

Since the mean blood pressure either was unchanged or rose during hyperventilation (Table II), it is clear that the recorded decreases in cerebral blood flow must have been due to some change localized in the brain, and by far the most likely cause is constriction of cerebral blood vessels. These findings, therefore, lend strong support to the already prevalent belief $(7,8,10,20)$ that the cerebral vessels are specifically regulated by the $\mathrm{CO}_{2}$ tension to which they are exposed. This attractive and seemingly well-founded conception was recently called into question $(10,18)$ because the first quantitative measurements of cerebral blood flow ever to be made under conditions approaching the normal $(18,19)$ indicated that the cerebral circulation as a whole is influenced much more strongly by changes in $\mathrm{pO}_{2}$ than in $\mathrm{pCO}_{2}$, and no evidence could be obtained that the response to $\mathrm{pCO}_{2}$ was marked enough to warrant confidence in a specific regulating function by this agent. The measurements of total cerebral blood flow were made on monkeys, whereas those on which the belief in the specificity of $\mathrm{CO}_{2}$ was based were semi-quantitative observations on the pial or cortical circulation in cats.

The possibility of a species difference has not yet been evaluated, but the most important question, viz., the behavior of man, is answered unequivocally by our present data: the total cerebral circulation of man resembles the pial or cortical circulation of the cat and not the total cerebral circulation of the monkey in its response to hypocapnia. The possible implications of this surprising conclusion will not be discussed further at this time than to point out that the most obvious interpretation-that the intrinsic control by $\mathrm{pCO}_{2}$ is better developed in the cat than in the monkey -is not necessarily justified. It may be that the effects on the subcortical areas in the monkey are equal but opposite to those in the cortex, and thus the total blood flow does not change while flow in the cortex does. It is possible that the response to $\mathrm{pCO}_{2}$ is more highly developed and, therefore, more subject to derangement by narcosis and experimental manipulations in the monkey 
than in the cat. Comparisons of the adequacy of the methods used in these various studies strongly favor the monkey experiments because in these total cerebral blood flow was actually measured, whereas in the cat experiments, changes in blood flow were inferred either from changes in the caliber of pial blood vessels (20), or from changes in temperature of a special thermocouple inserted in the cortex (21). The limitations of these methods are considered elsewhere (10). The possible influence of anesthesia on the cerebral vasoconstriction associated with acapnia will have to be settled by appropriate studies on man; it is unlikely that corresponding data can be obtained in animals before and after the induction of anesthesia.

Cerebral metabolism. From the cerebral arteriovenous $\mathrm{O}_{2}$ difference and the volume of cerebral blood flow, the cerebral $\mathrm{O}_{2}$ uptake can, of course, be computed directly. The values obtained are shown in Table III, and the percentile changes during hyperventilation are given in Table IV. One of the most interesting results of these studies is the difference in this respect between the two types of hyperventilation; though active hyperpnea was associated with a consistent and statistically significant increase in cerebral $\mathrm{O}_{2}$ uptake, passive hyperventilation of approximately the same degree and"in the same subjects was not. Since the indicated increase in cerebral $\mathrm{O}_{2}$ uptake occurred only when the hypocapnia was induced voluntarily, this cannot have been a simple experimental artifact related to imperfect understanding of the true contours of the arterial and venous $\mathrm{N}_{2} \mathrm{O}$ curves, nor can it have been due entirely to an acceleration of cerebral metabolism by alkalosis or by a subnarcotic concentration of $\mathrm{N}_{2} \mathrm{O}$. The most probable cause appears to be an actual increase in cerebral $\mathrm{O}_{2}$ uptake associated with the voluntary hyperpnea. If the relatively mild cortical activity, involved in maintaining an arbitrary respiratory cycle in accordance with a signal bell ringing every 10 seconds, is sufficient to produce a measurable increase in the total amount of $\mathrm{O}_{2}$ used by the brain, a high degree of lability in this function is indicated. If the cerebral arteriovenous $\mathrm{O}_{2}$ difference during passive hyperventilation can change so as to counterbalance precisely the associated decrease in blood flow, the delicacy with which these two factors are adjusted in relation to cerebral metabolism (18) becomes evident.

The absence of significant decrease in cerebral $\mathrm{O}_{2}$ consumption associated with a mild diminution in cerebral blood flow in these experiments places them in the same category with the first effects of mild hemorrhage in anesthetized monkeys (18). In both cases, the decrease in volume flow of blood was fully compensated by an increase in the arteriovenous $\mathrm{O}_{2}$ difference, and the total amount of $\mathrm{O}_{2}$ taken up by the brain did not fall. In the monkeys, there were no signs of cerebral deterioration at this time, but the criteria (wink reflex, unimpaired respiratory activity) were relatively crude, and the presence of anesthesia would already have brought about the counterpart of the more subtle derangements of which signs were evident in our human subjects. When the cerebral ischemia became too marked to be compensated by increasing the arteriovenous $\mathrm{O}_{2}$ difference, marked deterioration of cerebral and medullary functions rapidly ensued in monkeys (18), but we have not made any comparable experiments on man.

The coincidence of mild impairment of cerebral functions with undiminished or actually increased cerebral $\mathrm{O}_{2}$ consumption may be accounted for in several ways. It is possible that the metabolism associated with consciousness constitutes a relatively small fraction of the total cerebral $\mathrm{O}_{2}$ uptake, and its behavior is obscured therefore by that of the great mass of brain tissue. This interpretation is not in accord with our finding of a significant increase in total cerebral $\mathrm{O}_{2}$ uptake during voluntary hyperventilation. A more probable explanation is that the average $\mathrm{pO}_{2}$ to which the cortical cells were subjected was significantly diminished during hyperventilation, since the cerebral venous $\mathrm{pO}_{2}$ then was 37 to 42 per cent lower than before (p. 114), and the arterial $\mathrm{pO}_{2}$ was not appreciably increased. Even though the product of the decreased blood flow by the increased arteriovenous $\mathrm{O}_{2}$ difference indicated no change, or even an increase, this in itself means that the venous blood leaving the brain had to be considerably lower in $\mathrm{O}_{2}$ content and tension than before. A corresponding change in $\mathrm{pO}_{2}$ within the actively metabolizing cells of the cortex 
seems reasonable to assume. Finally, it is possible that the cortical and subcortical areas behave differently, perhaps oppositely. Our method is incapable of detecting any but the total change in blood flow or in $\mathrm{O}_{2}$ uptake in the brain, and there seems no point in further speculation along these lines at present.

It is interesting to note (Table IV) that the fall in $\mathrm{pCO}_{2}$ in cerebral venous blood during hyperventilation was considerably less than that in arterial. This is undoubtedly a reflection of the concomitant diminution in blood flow, which tends to conserve the $\mathrm{CO}_{2}$ produced by cerebral metabolism and thus partially to compensate for the profound arterial hypocapnia (26).

Cardiac output. It is seen in Tables II and IV that cardiac output per minute was not significantly changed during voluntary hyperpnea but showed a consistent fall averaging 11 per cent during passive hyperventilation. In each type of hyperventilation, stroke volume was the function primarily depressed, the heart rate increasing in both, but, in the case of the active process, to a degree sufficient to keep the minute volume from falling. The decrease in cardiac minute volume during passive hyperventilation is statistically significant. Examination of the ballistocardiograms discloses the fact that the decrease in stroke volume occurs during the inspiratory phase when the thorax is being expanded by a positive intrapulmonary pressure. This would be expected to cause a sharp decrease in venous return to the right side of the heart which would shortly be reflected in a decrease in left ventricular output. The fact that in period IV (Table II), immediately after the cessation of overbreathing, the outputs per beat and per minute both tend to revert nearly to the control value is evidence that the changes in cardiac output are the result of the mechanical factors associated with the hyperventilation rather than the chemical alterations in the blood; the latter would not change appreciably in so short a time after the cessation of overbreathing.

These results are at variance with the striking increase in cardiac output during active hyperventilation found with the acetylene method (22). They confirm recent studies (23) made by the direct Fick method in which cardiac output was found to fall about 13 per cent during passive hyperventilation of the type used here. The two types of hyperventilation employed in these experiments could have different effects on cardiac output for two reasons: the active type entails voluntary muscular exertion that is lacking in the passive one, while the latter contains a positive intrapulmonary pressure factor that is lacking in the former. Evaluation of these influences is beyond the scope of the present investigation. Other effects on the ballistocardiogram of changing intrathoracic pressures are the subject of a separate report (24).

Blood pressure. Both the mean and the auscultatory values (Tables II and IV) showed a moderate but not statistically significant rise during either type of hyperventilation. In no case was there a fall comparable with that observed in anesthetized animals (3) and humans (4). This discrepancy is probably due to a depression by the narcotic drug of the reactivity of cerebral blood vessels to the constrictor influence of acapnia. The brain cells then suffer a drop in $\mathrm{pCO}_{2}$ when acapnia is produced because the diffusion gradient for $\mathrm{CO}_{2}$ is increased, and there is no effective compensation by restriction of the volume of blood irrigating them.

Magnitude of cerebral blood flow and metabolism. Since our calculations of cerebral blood flow are based on the percentage content of $\mathrm{N}_{2} \mathrm{O}$ in the arterial and cerebral venous blood and the solubility coefficient of the gas in the brain, they yield a figure for blood flow per unit weight and are reported in terms of 100 grams of brain. A reasonable approximation to the total values can be obtained by adopting an acceptable average figure for brain weight in normal adult males, and a calculation of this type employing the factor 1400 grams is shown in Table V. These figures represent the means of the two series of control estimations (Table III), and they pertain solely to the then existing state of physical and mental inactivity in the recumbent position.

It is interesting to note that according to these calculations about one-fifth of the total cardiac output and about one-quarter of the total $\mathrm{O}_{2}$ consumption were required to satisfy the needs of the brains of these subjects under these circumstances. Their average weight was approximately $70 \mathrm{kgm}$., and, therefore, the estimated brain weight repre- 
TABLE V

Total cerebral blood flow and cerebral oxygen consumption (assuming a brain weight of 1400 grams) and their respective fractions of cardiac output and total oxygen consumption

\begin{tabular}{|c|c|c|c|c|}
\hline \multirow[b]{2}{*}{ Subject } & \multicolumn{2}{|c|}{$\begin{array}{c}\text { Cerebral blood } \\
\text { flow }\end{array}$} & \multicolumn{2}{|c|}{$\begin{array}{l}\text { Cerebral oxygen } \\
\text { consumption }\end{array}$} \\
\hline & & $\begin{array}{c}\text { Fraction } \\
\text { of cardiac } \\
\text { output }\end{array}$ & & $\begin{array}{c}\text { Fraction } \\
\text { of total } \mathrm{O}_{2} \\
\text { uptake by } \\
\text { body }\end{array}$ \\
\hline $\begin{array}{l}\text { S. H. } \\
\text { L. E. } \\
\text { M. H. } \\
\text { D. M. } \\
\text { W. H. }\end{array}$ & \begin{tabular}{|c} 
ml. per minute \\
826 \\
925 \\
896 \\
1050 \\
938
\end{tabular} & $\begin{array}{c}\text { per cent } \\
20.2 \\
18.2 \\
20.4 \\
21.4 \\
20.0\end{array}$ & \begin{tabular}{|c|} 
ml. per minute \\
55 \\
64 \\
60 \\
69 \\
62
\end{tabular} & $\begin{array}{c}\text { per cent } \\
20.1 \\
24.0 \\
21.6 \\
29.8 \\
24.4\end{array}$ \\
\hline Mean & 927 & 20.0 & 62 & 24.0 \\
\hline
\end{tabular}

The figures used for these calculations are the averages of the two resting (control) values in each subject.

sents 2 per cent of the total. These figures speak for themselves as far as the magnitudes of cerebral blood flow and metabolism relative to the rest of the body are concerned. The changes which they would undergo under conditions of altered cerebral, muscular, and visceral activity and under the influence of drugs and other agencies are at present matters for conjecture, as are also the variations to be expected between the sexes, at different ages, and under the influence of various pathological processes involving the brain, the cardiovascular system, the metabolism, and the blood. Our findings in monkeys (18) indicated that the "physiological" range for cerebral $\mathrm{O}_{2}$ uptake (i.e., the range of variation that could be undergone without engendering irreversible or slowly reversible changes in cerebral functional activity) was from about half to nearly double the resting "normal." No comparable values for man are at present available, and even those for the monkey are subject to the restrictions imposed by the experimental procedures (anesthesia, extensive operation, systemic anticoagulants and diversion of the cerebral arterial stream into a system of glass and rubber tubing). Any of these is a potential source of reduction in cerebral blood flow and metabolism, and the effectiveness of the anesthetics in this regard was clearly demonstrated (18).

For these reasons, we suggested (18) that the highest "normal" values in the monkey were probably the proper ones to use as the basis for expectations in intact man. These values in monkeys were, for cerebral blood flow and $\mathrm{O}_{2}$ consumption, 74 and $4.5 \mathrm{ml}$. per 100 grams per minute, which would amount to 1040 and $63 \mathrm{ml}$. per minute in a 1400 -gram brain. The corresponding normal resting values obtained in the present experiments on men were 59 to 75 (mean 66) and 3.9 to 4.9 (mean 4.4) ml. per 100 grams per minute; the means for a 1400 gram brain would be 927 and $62 \mathrm{ml}$. per minute (Table V). Since the monkey experiments involved no assumptions as to the measurement of cerebral blood flow, the fact that even one of them yielded results that were as high as those obtained by a less direct method in intact men indicates that our present estimates in man probably are not excessive. It also confirms the validity of the inferences drawn from the monkey experiments.

As far as we are aware, the figures in Table $\mathrm{V}$ are the first of the kind to become available. They are presented as a first step toward the establishment of a new set of normals, but they are also an example of the possibilities with respect to clinical medicine of some of the methods that have been employed in recent researches related to the war effort. It is to be hoped that the collaboration among various types of laboratory workers and clinicians which has made possible the development, and utilization for specific military problems, of new technics for the quantitative measurement of various functions in normal young men, will be continued after the incentive and financial support related to the war have ceased to operate. In the opinion of the authors, one of the greatest possibilities for securing an advantage to human welfare out of the wastage of the present war lies here, for in the past advances in clinical medicine have invariably followed the introduction of new methods, and the number of these developed during the past few years is without precedent.

\section{SUMMARY AND CONCLUSIONS}

1. Hyperventilation of moderate intensity was produced either voluntarily or passively in 5 normal young men lying recumbent at sea level. The effects on the following functions were studied: 
cerebral blood flow (by the $\mathrm{N}_{2} \mathrm{O}$ method (11)), cerebral arteriovenous $\mathrm{O}_{2}$ difference, cerebral $\mathrm{O}_{2}$ consumption, cardiac output (by the ballistocardiograph (12)), arterial blood pressure, pulse rate, pulmonary ventilation, and total $\mathrm{O}_{2}$ consumption.

2. Cerebral blood flow invariably diminished, the mean decreases during active and passive hyperventilation being 33 (range 12 to 44 ) and 35 (range 29 to 51 ) per cent of the control value. Cardiac output was reduced significantly ( 2 to 19 , average 11 per cent) during passive hyperventilation, but during the active process it was maintained by a concomitant tachycardia. Blood pressure did not fall in any case and tended to rise in most, though not significantly. The cerebral arteriovenous $\mathrm{O}_{2}$ difference invariably increased (41 to 84 , average 58 per cent). Cerebral $\mathrm{O}_{2}$ consumption showed a consistent and significant increase during active hyperventilation ( 5 to 35 , average 15 per cent), no change during passive. Definite signs of impairment of cerebral functions were observed in 5 instances, of tetany in 3.

3. These findings support the belief that cerebral vasoconstriction is one of the important results of hyperventilation, carried out voluntarily or passively with 21 per cent $\mathrm{O}_{2}$ in normal young men lying at rest at sea level.

4. The increase in cerebral $\mathrm{O}_{2}$ consumption during active hyperventilation is attributed to an actual increase in cerebral metabolic activity, since no corresponding change was associated with passive hyperventilation to the same extent.

5. The mean findings for cerebral blood flow and $\mathrm{O}_{2}$ consumption at rest, recalculated on a basis of a 1400-gram brain, came to 927 and 62 ml. per minute, which are practically identical with the highest "normal" values (1040 and 63 mi.) calculated from direct measurements in monkeys (18). This indicates that the present estimates probably are not excessive. According to these mean values, about 20 per cent of the total cardiac output and about 24 per cent of the total $\mathrm{O}_{2}$ consumption are dedicated to the requirements of the brain (about 2 per cent of the body weight) in normal young men at physical and mental rest at sea level. The mean $\mathrm{QO}_{2}$ for the normal resting human brain in these subjects was 13.2 (range 11.7 to 14.7 ).
The collaboration of Dr. Isaac Starr in conjunction with the use of the ballistocardiograph and the interpretation of the records is gratefully acknowledged, as is that of Dr. C. K. Friedland in the performance of some of the experiments. The seven conscientious objectors used as subjects in the present study proved to be willing, cooperative, highly motivated, and unusually intelligent, and we are glad to record our appreciation of their superlative qualities for such purposes.

\section{BIBLIOGRAPHY}

1. Rushmer, R. F., Boothby, W. M., and Hinshaw, H. C., Some effects of hyperventilation with special reference to aviation medicine. Proc. Staff Meet. Mayo Clin., 1941, 16, 801.

2. Hinshaw, H. C., Rushmer, R. F., and Boothby, W. $M$., The hyperventilation syndrome and its importance in aviation. J. Aviat. Med., 1943, 14, 100.

3. Dale, H. H., and Evans, C. L., The effects on the circulation of changes in the carbon dioxide content of the blood. J. Physiol., 1922, 56, 125.

4. Seevers, M. H., Stormont, R., Hathaway, H. R., and Waters, R. M., Respiratory alkalosis during anesthesia. An experimental study in man. J.A.M.A., 1939, 113, 2131.

5. Engel, G. L., Romano, J., Ferris, E. B., Webb, J. P., and Stevens, C. D., A simple method of determining frequency spectrums in the electroencephalogram. Arch. Neurol. Psychiat., 1944, 51, 134.

6. Best, C. H., and Taylor, N. B., The Physiological Basis of Medical Practice. Williams and Wilkins. Baltimore, 1943.

7. Lennox, W. G., and Gibbs, E. L., The blood flow in the brain and the leg of man, and the changes induced by alteration of blood gases. J. Clin. Invest., 1932, 11, 1153.

8. Gibbs, F. A., Gibbs, E. L., and Lennox, W. G., Changes in human cerebral blood flow consequent on alterations in blood gases. Am. J. Physiol., $1935,111,557$.

9. Ferris, E. B., Objective measurement of relative intracranial blood flow in man. Arch. Neurol. Psychiat., 1941, 46, 377.

10. Symposium on cerebral circulation. Federation Proceedings, 1944, 3, 131, 139 and 144.

11. Kety; S. S., and Schmidt, C. F., The determination of cerebral blood flow in man by the usse of nitrous oxide in low concentrations. Am. J. Physiol., 1945, 143, 53.

12. Starr, I., Rawson, A. J., Schroeder, H. A., and Joseph, N. R., Studies on the estimation of cardiac output in man, and of abnormalities in cardiac function, from the heart's recoil and the blood's impacts: the ballistocardiogram. Am. J. Physiol., 1939, 127, 1.

13. Cournand, A., Ranges, H. A., and Riley, R. L., Comparison of results of the normal ballistocardiogram and a direct Fick method in measuring the cardiac output in man. J. Clin. Invest., 1942, 21, 287. 
14. Peters, J. A., and Van Slyke, D. D., Quantitative Clinical Chemistry. Williams and Wilkins, Baltimore, 1931.

15. Symposium on cardiac output. Federation Proceedings, 1945,4 , in press.

16. Davies, P. W., and Brink, F., Jr., Direct measurement of brain oxygen concentration with a platinum electrode. Federation Proceedings, 1942, 1, 19; Rev. Sci. Inst., 1942, 13, 524.

17. Davis, E. W., McCulloch, W. S., and Roseman, E., Rapid changes in the oxygen tension of cerebral cortex during induced convulsions. Am. J. Psychiat., 1944, 100, 825.

18. Schmidt, C. F., Kety, S. S., and Pennes, H. H., The gaseous metabolism of the brain of the monkey. Am. J. Physiol., 1945, 143, 33.

19. Dumke, P. R., and Schmidt, C. F., Quantitative measurement of cerebral blood flow in the macacque monkey. Am. J. Physiol., 1943, 138, 421.

20. Wolf, H. G., and Lennox, W. G., Cerebral circulation. XII. The effect on pial vessels of variations in the oxygen and carbon dioxide content of the blood. Arch. Neurol. Psychiat., 1930, 23, 1097.

21. Schmidt, C. F., and Pierson, J. C., The intrinsic regulation of the blood vessels of the medulla oblongata. Am. J. Physiol., 1934, 108, 241 ; and Hendrix, J. P., The action of chemical substances on cerebral blood vessels. Proc. Assoc. Res. in Nerv. and Ment. Dis., 1938, 18, 229.

22. Grollman, A., Cardiac Output of Man in Health and Disease. C. C. Thomas, Baltimore, 1932.

23. Barach, A. L., Personal communication (to be published).

24. Starr, I., and Friedland, C. K., On the cause of the respiratory variation of the ballistocardiogram, with a note on sinus arrhythmia. In press.

25. Gibbs, E. L., Gibbs, F. A., Lennox, W. G., and Nims, L. F., Regulation of cerebral carbon dioxide. Arch. Neurol. Psychiat., 1942, 47, 879.

26. Nims, L. F., Gibbs, E. L., and Lennox, W. G., Arterial and cerebral venous blood changes produced by altering arterial carbon dioxide. J. Biol. Chem., 1942, 145, 189. 